\title{
Does Economic Policy Uncertainty Predict Exchange Rate Returns and Volatility? Evidence from a Nonparametric Causality-in-Quantiles Test
}

\author{
Mehmet Balcilar \\ Eastern Mediterranean University, Turkey; \\ University of Pretoria, South Africa \\ and \\ IPAG Business School, Paris, France \\ mehmet@mbalcilar.net \\ Rangan Gupta \\ University of Pretoria, South Africa \\ and \\ IPAG Business School, Paris, France \\ rangan.gupta@up.ac.za \\ Clement Kyei \\ University of Pretoria, South Africa \\ kweku.shaker@gmail.com \\ Mark E. Wohar \\ University of Nebraska-Omaha, USA \\ mwohar@unomaha.edu \\ and \\ Loughborough University, UK
}

December 24, 2015

JEL Codes: C32; C53; E60; F31

Keywords: Economic Policy Uncertainty; Exchange Rate Returns; Volatility; Nonparametric Quantile Causality; Developed and Emerging Markets 


\begin{abstract}
Recent studies have analysed the ability of measures of uncertainty to predict movements in macroeconomic and financial variables. The objective of this paper is to employ the recently proposed nonparametric causality-in-quantiles test to analyse the predictability of returns and volatility of sixteen U.S. dollar-based exchange rates (for both developed and developing countries) over the monthly period of 1999:01-2012:03, based on information provided by a news-based measure of relative uncertainty, i.e., the differential between domestic and U.S. uncertainties. The causality-in-quantile approach allows us to test for not only causality-in-mean ( $1^{\text {st }}$ moment), but also causality that may exist in the tails of the joint distribution of the variables. In addition, we are also able to investigate causality-in-variance (volatility spillovers) when causality in the conditional-mean may not exist, yet higher order interdependencies might emerge. We motivate our analysis by employing tests for nonlinearity. These tests detect nonlinearity, as well as the existence of structural breaks in the exchange rate returns, and in its relationship with the EPU differential, implying that the Granger causality tests based on a linear framework is likely to suffer from misspecification. The results of our nonparametric causalityin-quantiles test indicate that for seven exchange rates EPU differentials have a causal impact on the variance of exchange rate returns but not on the returns themselves at all parts of the conditional distribution. We also find that EPU differentials have predictive ability for both exchange rate returns as well as the return variance over the entire conditional distribution for four exchange rates.
\end{abstract}

JEL Codes: C32; C53; E60; F31

Keywords: Economic Policy Uncertainty; Exchange Rate Returns; Volatility; Nonparametric Quantile Causality; Developed and Emerging Markets 


\section{Introduction}

The foreign exchange market is by far the largest and most liquid financial market in the world. As reported in the Triennial Survey of global foreign exchange market volumes of the Bank for International Settlement (BIS), the average daily turnover was 5.345 trillion of U.S. dollars in September of 2013. Exchange rate predictability is of interest to not only investors, but also exporters and importers - retailers and consumers, who ultimately take decisions based on the value of the domestic currency, and also on its volatility. Additionally, policymakers are concerned with pass-through - a major mechanism by which the exchange movements affect domestic economic aggregates. Hence, accurate prediction of exchange rate returns and volatility is of paramount importance to various economic agents. Naturally, the literature on predictability of exchange rate returns and volatility is voluminous to say the least, with detailed literature review provided by Rossi (2013) and Pilbeam and Langeland (2015). One common theme that emerges out of this literature is that, despite the great need, the task of predicting exchange rate movements is an arduous task based on fundamentals.

Against this backdrop, the objective of our paper is to use the recently proposed nonparametric causality-in-quantiles test by Balcilar et al., (forthcoming) to analyse the predictability of returns and volatility of sixteen U.S. dollar-based exchange rates over the monthly period of 1999:012012:03, based on information provided by a news-based measure of relative uncertainty, i.e., the differential between domestic and U.S. uncertainties. Using the uncertainty measures developed by Brogaard and Detzel (2015), we concentrate on the dollar-based exchange rates for both developed and developing countries/regions namely: Australia, Brazil, Canada, China, Euro area, Hong Kong, India, Japan, Malaysia, Mexico, Russian Federation, South Korea, South Africa, Sweden, Switzerland and UK. The choice of dollar-based exchange rates when analysing uncertainty is clear, given the widely-accepted safe-haven notion associated with the U.S. dollar (see Ciner et al., (2013) for a detailed discussion in this regard). The causality-in-quantiles test that 
we employ in this paper, combines the frameworks of k-th order causality of Nishiyama et al., (2011) and quantile causality of Jeong et al., (2012), and hence, can be considered to be a more general version of the former. The causality-in-quantile approach has the following novelties: Firstly, it is robust to misspecification errors as it detects the underlying dependence structure between the examined time series; this could prove to be particularly important, as it is well known exchange rates display nonlinear dynamics (Rapach and Wohar, 2006) - something we show below as well, not only for the exchange rate on its own, but also in its relationship with the EPU differential. Secondly, via this methodology, we are able to test for not only causality-inmean $\left(1^{\text {st }}\right.$ moment), but also causality that may exist in the tails of the joint distribution of the variables, which in turn, is particularly important if the dependent variable has fat-tails something we show below to hold for exchange rate returns. Finally, we are also able to investigate causality-in-variance thereby volatility spillovers, as some times when causality in the conditional-mean may not exist, yet higher order interdependencies might emerge.

To the best of our knowledge, this is the first paper to employ a causality-in-quantiles approach to study the predictability of exchange rate returns and its volatility simultaneously, based on relative EPU. In the process, we contribute to a recent, but growing literature that has originated in the wake of the "Great Recession", whereby studies have aimed to develop various tangible measures of uncertainty (see Strobel (2015) for a detailed literature review on alternative methods of measuring uncertainty), and then in turn, have analysed the ability of these measures of uncertainty to predict movements in macroeconomic variables (Balcilar, Gupta and Jooste, 2014; Karnizova and Li, 2014; Balcilar, Gupta and Segnon, 2015), equity markets (Gupta et al., 2014; Balcilar, Gupta, Kim and Kyei, 2015; Balcilar, Gupta, Modise and Muteba Mwamba, 2015; Bekiros, Gupta and Majumdar, 2015; Brogaard and Detzel, 2015; Balcilar, Gupta and Kyei, forthcoming; Bekiros et al., forthcoming; Li et al., forthcoming), housing markets (El Montasser et al., forthcoming; André et al., forthcoming), and commodity markets (Bekiros, Gupta and 
Paccagnini, 2015; Balcilar, Gupta and Pierdzioch, 2015; Andreasson et al., forthcoming; Balcilar et al., forthcoming), and uncertainty itself (Gupta et al., 2015). Interestingly, as far as the relationship between uncertainty on exchange rate returns and volatility is concerned, it is limited to only few conditional-mean based studies. On one hand, Benigno et al., (2012) uses vector autoregressive (VAR) and panel VAR models to analyse the impact of domestic uncertainties (modelled through conditional volatilities of monetary policy, inflation-target and productivity shocks) on the dollar-based real exchange rates of the G6 countries. While on the other hand, Colombo (2013) uses a VAR model to analyse the impact of U.S. uncertainty on the nominal euro-dollar exchange rate, and Sin (2015) using the same approach to study the effect of shocks to Chinese uncertainty on the real exchange rates of Taiwan and Hong Kong relative to the Chinese Yuan. In general, these studies find a significant impact on exchange rates following uncertainty shocks. Krol (2014) is the only study that analyses the contemporaneous effect of domestic and US uncertainties separately on the volatility of ten dollar-based nominal exchange rates of industrialized and developing countries based on linear regressions. The author finds that, for the more integrated industrial economies, there is strong evidence that both home country and U.S. economic policy uncertainty increases currency volatility during recessions, while, for the less integrated emerging economies, only home country economic policy uncertainty increases exchange rate volatility during recessionary episodes. Note that the last three studies use newspaper-based measures of uncertainty. No attempt has been made so far to predict exchange rate returns and volatility based on economic policy uncertainty over the entire conditional distributions of these variables, something that one may find surprising, given the importance of exchange rate movements, and hence, this is what we aim to investigate in this paper.

An important question that we have been silent so far about, but requires answering is: What is the intuitive and theoretical explanations that can lead one to believe that relative EPU can predict exchange rate returns and its volatility? Common knowledge suggests that if 
domestic uncertainty is higher than uncertainty in the foreign economy at a given point in time, then domestic agents would prefer to invest into assets denominated in the foreign currency, implying that the value of the domestic currency relative to the foreign currency would depreciate, i.e., the returns and volatility (defined as squared returns) on domestic currency would be affected. In addition, besides this direct channel, given that returns of financial assets are functions of the state of the economy, which in turn, are subject to fluctuations caused by uncertainty among other factors, would suggest an indirect channel through which uncertainty can affect exchange rate returns and volatility. Formalization of these channels based on new Keynesian general equilibrium frameworks can be found in the works of Martin and Urrea (2007) and Benigno et al., (2012). The remainder of the paper is organized as follows: Section 2 presents the methodology, while Section 3 discusses the data and the results. Finally Section 4 concludes.

\section{Methodology}

We present here a novel methodology, as proposed by Balcilar et al., (forthcoming), for the detection on nonlinear causality via a hybrid approach based on the frameworks of Nishiyama et al., (2011) and Jeong et al., (2012). We denote dollar-based exchange rate returns as $\left(y_{t}\right)$ and the differential between own-country EPU and the U.S. EPU as $\left(x_{t}\right)$. Following Jeong et al., (2012), the quantile-based causality is defined as follows: ${ }^{1} x_{t}$ does not cause $y_{t}$ in the $\theta$-quantile with respect to the lag-vector of $\left\{y_{t-1}, \ldots, y_{t-p}, x_{t-1}, \ldots, x_{t-p}\right\}$ if

$$
Q_{\theta}\left(y_{t} \mid y_{t-1}, \ldots, y_{t-p}, x_{t-1}, \ldots, x_{t-p}\right)=Q_{\theta}\left(y_{t} \mid y_{t-1}, \ldots, y_{t-p}\right)
$$

$x_{t}$ is a prima facie cause of $y_{t}$ in the $\theta$-th quantile with respect to

$$
\begin{aligned}
& \left\{y_{t-1}, \ldots, y_{t-p}, x_{t-1}, \ldots, x_{t-p}\right\} \text { if } \\
& \quad Q_{\theta}\left(y_{t} \mid y_{t-1}, \ldots, y_{t-p}, x_{t-1}, \ldots, x_{t-p}\right) \neq Q_{\theta}\left(y_{t} \mid y_{t-1}, \ldots, y_{t-p}\right)
\end{aligned}
$$

\footnotetext{
${ }^{1}$ The exposition in this section closely follows Nishiyama et al., (2011) and Jeong et al., (2012).
} 
where $Q_{\theta}\left(y_{t} \mid \cdot\right)$ is the $\theta$-th quantile of $y_{t}$ depending on $t$ and $0<\theta<1$.

Let $Y_{t-1} \equiv\left(y_{t-1}, \ldots, y_{t-p}\right), \quad X_{t-1} \equiv\left(x_{t-1}, \ldots, x_{t-p}\right), \quad Z_{t}=\left(X_{t}, Y_{t}\right), \quad$ and $F_{y_{t} \mid Z_{t-1}}\left(y_{t} \mid Z_{t-1}\right)$ and $F_{y_{t} \mid Y_{t-1}}\left(y_{t} \mid Y_{t-1}\right)$ denote the conditional distribution functions of $y_{t}$ given $Z_{t-1}$ and $Y_{t-1}$, respectively. The conditional distribution $F_{y_{t} \mid Z_{t-1}}\left(y_{t} \mid Z_{t-1}\right)$ is assumed to be absolutely continuous in $y_{t}$ for almost all $Z_{t-1}$. If we denote $Q_{\theta}\left(Z_{t-1}\right) \equiv Q_{\theta}\left(y_{t} \mid Z_{t-1}\right)$ and $Q_{\theta}\left(Y_{t-1}\right) \equiv$ $Q_{\theta}\left(y_{t} \mid Y_{t-1}\right)$, we have $F_{y_{t} \mid Z_{t-1}}\left\{Q_{\theta}\left(Z_{t-1}\right) \mid Z_{t-1}\right\}=\theta$ with probability one. Consequently, the hypotheses to be tested based on definitions (1) and (2) are:

$$
\begin{aligned}
& H_{0}=P\left\{F_{y_{t} \mid Z_{t-1}}\left\{Q_{\theta}\left(Y_{t-1}\right) \mid Z_{t-1}\right\}=\theta\right\}=1 \\
& H_{0}=P\left\{F_{y_{t} \mid Z_{t-1}}\left\{Q_{\theta}\left(Y_{t-1}\right) \mid Z_{t-1}\right\}=\theta\right\}=1
\end{aligned}
$$

Jeong et al., (2012) employs the distance measure $J=\left\{\varepsilon_{t} E\left(\varepsilon_{t} \mid Z_{t-1}\right) f_{Z}\left(Z_{t-1}\right)\right\}$ where $\varepsilon_{t}$ is the regression error term and $f_{Z}\left(Z_{t-1}\right)$ is the marginal density function of $Z_{t-1}$. The regression error $\varepsilon_{t}$ emerges based on the null in (3), which can only be true if and only if $E\left[\mathbf{1}\left\{y_{t} \leq Q_{\theta}\left(Y_{t-1}\right) \mid Z_{t-1}\right\}\right]=\theta$ or equivalently $\mathbf{1}\left\{y_{t} \leq Q_{\theta}\left(Y_{t-1}\right)\right\}=\theta+\varepsilon_{t}$, where $\mathbf{1}\{\cdot\}$ is an indicator function. Jeong et al. (2012) specify the distance function as follows:

$$
J=E\left[\left\{F_{y_{t} \mid Z_{t-1}}\left\{Q_{\theta}\left(Y_{t-1}\right) \mid Z_{t-1}\right\}-\theta\right\}^{2} f_{Z}\left(Z_{t-1}\right)\right]
$$

In Eq. (3), it is important to note that $J \geq 0$, i.e., the equality holds if and only if $H_{0}$ in (5) is true, while $J>0$ holds under the alternative $H_{1}$ in Eq. (4). Jeong et al., (2012) show that the feasible kernel-based test statistic for $J$ has the following form:

$$
\hat{J}_{T}=\frac{1}{T(1-1) h^{2 p}} \sum_{t=p+1}^{T} \sum_{s=p+1, s \neq t}^{T} K\left(\frac{Z_{t-1}-Z_{s-1}}{h}\right) \hat{\varepsilon}_{t} \hat{\varepsilon}_{s}
$$

where $K(\cdot)$ is the kernel function with bandwidth $h, T$ is the sample size, $p$ is the lag-order, and $\hat{\varepsilon}_{t}$ is the estimate of the unknown regression error, which is estimated as follows:

$$
\hat{\varepsilon}_{t}=\mathbf{1}\left\{y_{t} \leq \hat{Q}_{\theta}\left(Y_{t-1}\right)-\theta\right\}
$$

$\hat{Q}_{\theta}\left(Y_{t-1}\right)$ is an estimate of the $\theta$-th conditional quantile of $y_{t}$ given $Y_{t-1}$. Below, we estimate $\hat{Q}_{\theta}\left(Y_{t-1}\right)$ using the nonparametric kernel method as: 


$$
\widehat{Q}_{\theta}\left(Y_{t-1}\right)=\hat{F}_{y_{t} \mid Y_{t-1}}^{-1}\left(\theta \mid Y_{t-1}\right)
$$

where $\hat{F}_{y_{t} \mid Y_{t-1}}\left(y_{t} \mid Y_{t-1}\right)$ is the Nadarya-Watson kernel estimator given by:

$$
\hat{F}_{y_{t} \mid Y_{t-1}}\left(y_{t} \mid Y_{t-1}\right)=\frac{\sum_{s=p+1, s \neq t}^{T} L\left(\frac{Y_{t-1}-Y_{s-1}}{h}\right) \mathbf{1}\left(y_{s} \leq y_{t}\right)}{\sum_{s=p+1, s \neq t}^{T} L\left(\frac{Y_{t-1}-Y_{s-1}}{h}\right)}
$$

with $L(\cdot)$ denoting the kernel function and $h$ the bandwidth.

In an extension of the Jeong et al., (2012) framework, we develop a test for the 2nd moment. In particular, we want to test the volatility causality running from the differential of own and foreign-country EPUs to exchange rate returns. Causality in the $k$-th moment generally implies causality in the $m$-th moment for $k<m$. Firstly, we employ the nonparametric Granger quantile causality approach by Nishiyama et al., (2011). In order to illustrate the causality in higher order moments, consider the following process for $y_{t}$ :

$$
y_{t}=g\left(Y_{t-1}\right)+\sigma\left(X_{t-1}\right) \varepsilon_{t}
$$

where $\varepsilon_{t}$ is a white noise process; and $g(\cdot)$ and $\sigma(\cdot)$ are unknown functions that satisfy certain conditions for stationarity. However, this specification does not allow for Granger-type causality testing from $x_{t}$ to $y_{t}$, but could possibly detect the "predictive power" from $x_{t}$ to $y_{t}^{2}$ when $\sigma(\cdot)$ is a general nonlinear function. Hence, the Granger causality-in-variance definition does not require an explicit specification of squares for $X_{t-1}$. We re-formulate Eq. (10) into a null and alternative hypothesis for causality in variance as follows:

$$
\begin{aligned}
& H_{0}=P\left\{F_{y_{t}^{2} \mid Z_{t-1}}\left\{Q_{\theta}\left(Y_{t-1}\right) \mid Z_{t-1}\right\}=\theta\right\}=1 \\
& H_{1}=P\left\{F_{y_{t}^{2} \mid Z_{t-1}}\left\{Q_{\theta}\left(Y_{t-1}\right) \mid Z_{t-1}\right\}=\theta\right\}<1
\end{aligned}
$$

To obtain a feasible test statistic for testing the null in Eq. (10), we replace $y_{t}$ in Eq. (6) - (9) with $y_{t}^{2}$. Incorporating the Jeong et al., (2012) approach we overcome the problem that causality in the conditional 1st moment (mean) imply causality in the 2 nd moment (variance). In order to overcome this problem, we interpret the causality in higher order moments using the following model: 


$$
y_{t}=g\left(X_{t-1}, Y_{t-1}\right)+\varepsilon_{t}
$$

Thus, higher order quantile causality can be specified as:

$$
\begin{aligned}
& H_{0}=P\left\{F_{y_{t}^{2} \mid Z_{t-1}}\left\{Q_{\theta}\left(Y_{t-1}\right) \mid Z_{t-1}\right\}=\theta\right\}=1 \quad \text { for } k=1,2, \ldots, K \\
& H_{1}=P\left\{F_{y_{t}^{2} \mid Z_{t-1}}\left\{Q_{\theta}\left(Y_{t-1}\right) \mid Z_{t-1}\right\}=\theta\right\}<1 \quad \text { for } k=1,2, \ldots, K
\end{aligned}
$$

Integrating the entire framework, we define that $x_{t}$ Granger causes $y_{t}$ in quantile $\theta$ up to $K$-th moment utilizing Eq. (11) to construct the test statistic of Eq. (6) for each $k$. However, it can be shown that it is impossible to combine the different statistics for each $k=1,2, \ldots, K$ into one statistic for the joint null in Eq. (14) because the statistics are mutually correlated (Nishiyama et al., 2011). To efficiently address this issue, we include a sequential-testing method as described Nishiyama et al. (2011) with some modifications. Firstly we test for the nonparametric Granger causality in the 1st moment $(k=1)$. Rejecting the null of non-causality means that we can stop and interpret this result as a strong indication of possible Granger quantile causality-in-variance. Nevertheless, failure to reject the null for $k=1$, does not automatically leads to no-causality in the 2 nd moment, thus we can still construct the tests for $k=2$. Finally, we can test the existence of causality-in-variance, or the causality-in-mean and variance successively. The empirical implementation of causality testing via quantiles entails specifying three important choices: the bandwidth $h$, the lag order $p$, and the kernel type for $K(\cdot)$ and $L(\cdot)$ in Eq. (6) and (9) respectively. In our study, the lag order of 1 is determined using the Schwarz Information Criterion (SIC) under a VAR comprising of exchange rate returns and the differential between own- and foreign-country EPUs. The SIC being parsimonious when it comes to choosing lags compared to other alternative lag-length selection criterion, helps us to prevent issues of overparametrization commonly associated with nonparametric approaches. The bandwidth value is selected using the least squares cross-validation method. Lastly, for $K(\cdot)$ and $L(\cdot)$ we employ Gaussian-type kernels. 


\section{Data and Empirical Results}

Our analysis is based on sixteen monthly U.S. dollar based exchange rates of Australia, Brazil, Canada, China, Euro area, Hong Kong, India, Japan, Malaysia, Mexico, Russian Federation, South Korea, South Africa, Sweden, Switzerland and UK, and the differential of the U.S. EPU from the respective domestic EPUs. Our period of analysis covers 1999:01-2012:03, with the start and end date being purely driven by data availability. The data on the U.S. dollar exchange rates for these countries are obtained from Bloomberg. Given that exchange rates were nonstationary, based on standard unit root tests, ${ }^{2}$ we work with exchange rate returns, which are in turn, obtained as the first-differences of the natural logarithmic values of the stock indexes expressed in percentages. The squared values of these returns measure the volatility of the exchange rate. The data on EPU for all the countries and the Euro area is derived from Brogaard and Detzel (2015). ${ }^{3}$ These authors construct the EPU indexes based on data from an internet search and count of articles that use key words associated with economic policy uncertainty in these countries. The source for their data is the Access World News database. Note that, we average the EPUs of France, Germany, Italy, The Netherlands and Spain to create a measure of the EPU for the Euro area. We work with differential between the natural logarithmic values of the EPU of a specific country or region and the natural logarithmic values of the EPU of the U.S. which, in turn are found to be stationary, based on standard unit root tests. ${ }^{4}$ Hence, the basic condition of stationarity of the variables required for our causality-in-quantiles approach holds with exchange rate returns and the various EPU differentials. Note that, we could compute

\footnotetext{
${ }^{2}$ Complete details of the unit root tests are available upon request from the authors.

${ }^{3}$ We thank Jonathan Brogaard for providing us with the EPU data. Note that, though Brogaard and Detzel (2015) created the EPU for 21 countries in an earlier version of the paper, they only concentrated on the US stock market in the published version.

${ }^{4}$ Theoretically, measures of uncertainty should be stationary. However, statistically, it could deviate from this due to the sample period considered. But, the unit root tests revealed that the natural logarithm of the EPUs on their own as well as in differential form, did not contain unit roots, and hence, could be used in levels in our analysis. Complete details of the unit root tests are available upon request from the authors.
} 
the EPU differentials without any issues, as all the EPUs were scaled by Brogaard and Detzel (2015), so that a positive value of the differential would indicate that the domestic EPU is higher than the U.S., while a negative value of the same would suggest a higher U.S. EPU relative to the domestic country.

\section{[INSERT TABLE 1]}

Table 1 provides the summary statistics of the sixteen exchange rate returns. The Brazilian Real has the highest mean returns and highest volatility, while the Australian dollar has the lowest returns, with the Hong Kong dollar the lowest variability. There is excess kurtosis in all cases, while all the returns, barring the Chinese Yuan, Hong Kong Dollar and the Swiss Franc, are positively skewed. More importantly, with the exception of the Euro, Japanese Yen and the Swiss Krona, all the exchange rate returns have non-normal distribution, as indicated by the strong rejection of Jarque-Bera statistic at 1 percent level of significance. Note, the Euro has a non-normal distribution at the 10 percent level of significance. This in turn, provides an initial motivation to look at the effect of the EPU differentials over the entire conditional distribution of exchange rate returns (and volatility), rather than just at the conditional-mean.

\section{[INSERT TABLE 2]}

Though our objective is to analyse the causality-in-quantiles running from EPU differentials to the exchange rate return and its volatility, for the sake of completeness and comparability, we also conducted the standard linear Granger causality test based on a VAR(1) model. The results have been reported in Table 2. As can be seen, barring the cases of the Barzilian Real relative to the U.S. dollar exchange rate returns, there is no evidence of predictability originating from the EPU differentials for the exchange rate returns in the other cases at the conventional 5 percent 
level of significance. If the cut-off limit is weakened to 10 percent, we observe predictability for the Chinese Yuan and the Euro. Overall, the evidence is weak, if not non-existent, in terms of the ability of the differential between domestic and U.S. EPUs in predicting exchange rate returns of the sixteen currencies considered.

\section{[INSERT TABLE 3]}

Next, to motivate the use of the nonparametric quantile-in-causality approach, we statistically investigate the possibility of nonlinearity in the relationship between the exchange rate returns and the EPU differentials. To this end, we apply the Brock et al., (1996, BDS) test on the residuals of an $\mathrm{AR}(1)$ model for exchange rate returns, and the exchange rate returns equation in the VAR(1) model involving the EPU differential. Barring the cases of the Euro, Japanese Yen, Swiss Franc and the British Pound, the BDS test, reported in Table 3, provides ample evidence of the rejection of the null of i.i.d. residuals at various embedded dimensions $(m)$, for all cases considered. These results provide strong evidence of nonlinearity in not only the exchange rate returns of the remaining twelve countries, but also in their relationship with its EPU differential. This means that, the result of causality based on the linear Granger causality test, cannot be deemed robust and reliable for the dollar-based exchange rates of the Brazilian Real and the Chinese Yuan.

\section{[INSERT TABLE 4]}

Next, we turn to the Bai and Perron (2003) test of multiple structural breaks, applied again to the AR(1) model for exchange rate returns, and the exchange rate return equation in the VAR(1) model involving the EPU differential. These results have been reported in Table 4. While there are no breaks in the AR(1) exchange rate returns model for the Euro, Hong Kong Dollar, Indian Rupee, Japanese Yen, and the Swiss Franc, there are at least one break for the remaining eleven dollar based exchange rate returns. More importantly, for the exchange rate returns equation in 
the $\operatorname{VAR}(1)$ model incorporating the EPU differentials, all the sixteen cases have at least one break. Not surprisingly most of the breaks are concentrated during the recent financial crisis or currency crisis of respective countries. So, as under the BDS test which detected nonlinearity, existence of structural breaks in the exchange rate returns, and in its relationship with the EPU differential, imply that the Granger causality tests based on a linear framework is likely to suffer from misspecification. Given the strong evidence of either nonlinearity or regime changes or both in all the relationships between exchange rate returns and the EPU differentials, we now turn our attention to the causality-in-quantiles test.

\section{[FIGURES 1 THROUGH 16 ABOUT HERE]}

In figures 1 through 16, we present the results obtained from the quantile causality test for the sixteen U.S. dollar-based exchange rate returns and volatility due to the EPU differentials. There are five cases in which there is no causality of EPU differentials to either exchange rate returns or return volatility. These are for the Australia dollar to US dollar exchange rate (Figure 1), the Japanese yen to US dollar exchange rate (Figure 8), the African Rand to US dollar exchange rate (Figure 13), the Swedish Krona to the US dollar exchange rate (Figure 14) and the British pound to the US dollar exchange rate (Figure 16). As can be seen the EPU differential contains no information of predictability for these exchange rate returns or exchange rate return volatility at any part of the conditional distribution ${ }^{5}$. In other words, EPU does not cause exchange rate returns or volatility of returns for the above mentioned exchange rates irrespective of whether exchange rate returns are high or low.

\footnotetext{
${ }^{5}$ One exception is in Figure 14 for the variance of the Swedish Krona exchange rate. EPU explains the variance at the 0.45 to 0.55 quantiles.
} 
For the following exchange rates the results indicate that EPU has a causal impact on the variance of exchange rate returns but not the returns themselves at all parts of the conditional distribution. These include the Bazialian Real to US dollar exchange rate (Figure 2), the Canadian dollar to the US dollar (Figure 3), the Hong Kong dollar to US dollar (Figure 6), Indian Rupee to US dollar exchange rate (Figure 7), Swiss Franc to US dollar (for quantile 0.2 to 0.8) (Figure 15). The South Korean Won to US dollar exchange rate show the EPU explaining the variance of returns at the 0.35 to 0.6 quantiles (Figure 9). For the Mexican Peso to US dollar exchange rate, EPU has predictive ability for the variance of exchange rate returns for quantiles 0.2 to 0.7 .

EPU differentials have predictive ability for both exchange rate returns as well as the return variance over the entire conditional distribution for the Chinese Yuan to US dollar exchange rate (Figure 4), the Malaysian Rinngit to US dollar exchange rate (Figure 10), the Russian Ruble to US dollar exchange rate (Figure 12). For the case of the Euro to the US dollar (Figure 5) the results indicate that EPU differentials have a causal link to exchange rate returns for quantiles 0.25 to 0.8 and for variance of returns at quantiles 0.15 to 0.7 .

So in sum, evidence that EPU differentials predict exchange rate returns is weak in the linear model. However, as we show, the standard Granger causality results cannot be relied upon due to the existence of nonlinearity and structural breaks. Given this, when we look into the nonparametric causality-in-quantiles test, which is robust to misspecifications, we find evidence of EPU differentials predicting returns and/or volatility of eleven of the sixteen exchange rates considered.

\section{Conclusions}

The news-based measures of uncertainty, as developed by Baker et al., (2015) and Brogaard and Detzel (2015), have gained popularity in a number of applications in macroeconomics and 
finance. This is likely due to the fact that data (not only for the US, but also other European and emerging economies) based on this approach is easily available for use, and does not require any complicated estimation of a model to generate it. To construct the index, Baker et al. (2015) and Brogaard and Detzel (2015) perform month-by-month searches of newspapers for terms related to economic and policy uncertainty.

The purpose of this paper is to employ the recently proposed nonparametric causality-inquantiles test to analyse the predictability of returns and volatility using Economic of sixteen U.S. dollar-based exchange rates (for both developed and developing countries) over the monthly period of 1999:01-2012:03, based on information provided by the above mentioned news-based measure of relative uncertainty, i.e., the differential between domestic and U.S. uncertainties. The causality-in-quantile approach allows us to test for not only causality-in-mean, but also causality that may exist in the tails of the joint distribution of the variables. Furthermore, we are also able to investigate causality-in-variance (volatility spillovers) that may occur when causality in the conditional-mean may not exist, yet higher order interdependencies might emerge.

We begin our analysis for the sake of completeness and comparability by conducting the standard linear Granger causality test based on a VAR(1) model. With the exception of the Barzilian Real relative to the U.S. dollar exchange rate returns, we find no evidence of predictability originating from the EPU differentials for stock returns in the other cases at the conventional 5 percent level of significance. Overall, the evidence is almost non-existent, in terms of the ability of the differential between domestic and U.S. EPUs in predicting exchange rate returns of the sixteen currencies considered. 
We motivate our nonparametric quantile-in-causality approach by employing tests for nonlinearity. These tests provide strong evidence of nonlinearity in not only the exchange rate returns of twelve countries, but also in their relationship with its EPU differential. These results imply that the Granger causality tests based on a linear framework is likely to suffer from misspecification. Given the strong evidence of either nonlinearity or regime changes or both in all the relationships between exchange rate returns and the EPU differentials, we now turn our attention to the causality-in-quantiles test.

We find that there are five cases in which there is no causality of EPU differentials to either exchange rate returns or return volatility. That is, EPU differentials do not cause exchange rate returns or volatility of returns for five exchange rates irrespective of whether exchange rate returns are how or low. The results indicate that for seven exchange rates EPU differentials have a causal impact on the variance of exchange rate returns but not on the returns themselves at all parts of the conditional distribution. We also find that EPU differentials have predictive ability for both exchange rate returns as well as the return variance over the entire conditional distribution for four exchange rates. As part of future research, it would be interesting to extend our analysis to a forecasting exercise as in, since in-sample predictability does not necessarily guarantee the same over the out-of-sample. 


\section{References}

André, C., Bonga-Bonga, L., and Gupta, R. (Forthcoming). The Impact of Economic Policy Uncertainty on US Real Housing Returns and their Volatility: A Nonparametric Approach. Journal of Real Estate Research.

Andreasson, P., Bekiros, S., Nguyen, D.K., and Uddin, G.S. (Forthcoming). Impact of speculation and economic uncertainty on commodity markets. International Review of Financial Analysis.

Bai, J. and Perron, P. 2003. Computation and analysis of multiple structural change models. Journal of Applied Econometrics 18, 1-22.

Balcilar, M., Bekiros, S., and Gupta, R. (Forthcoming). The role of news-based uncertainty indices in predicting oil markets: a hybrid nonparametric quantile causality method. Empirical Economics.

Balcilar, M., Gupta, R., and Jooste, C. (2014). The Role of Economic Policy Uncertainty in Forecasting US Inflation Using a VARFIMA Model. Department of Economics, University of Pretoria, Working Paper No. 201460.

Balcilar, M., Gupta, R., Kim, W-J., and Kyei, C. (2015). The Role of Domestic and Global Economic Policy Uncertainties in Predicting Stock Returns and their Volatility for Hong Kong, Malaysia and South Korea: Evidence from a Nonparametric Causality-in-Quantiles Approach. Department of Economics, University of Pretoria, Working Paper No. 201586.

Balcilar, M., Gupta, R., and Kyei, C. (Forthcoming). South African Stock Returns Predictability using Domestic and Global Economic Policy Uncertainty: Evidence from a Nonparametric Causality-in-Quantiles Approach. Frontiers in Finance and Economics.

Balcilar, M., Gupta, R., and Pierdzioch, C. (2015). Does Uncertainty Move the Gold Price? New Evidence from a Nonparametric Causality-in-Quantiles Test. Department of Economics, University of Pretoria, Working Paper No. 201592.

Balcilar, M., Gupta, R., and Segnon, M. (2015). The Role of Economic Policy Uncertainty in Predicting US Recessions: A Mixed-Frequency Markov-Switching Vector Autoregressive Approach. Department of Economics, University of Pretoria, Working Paper No. 20158.

Balcilar. M., Modise. M.P., Gupta. R., and Muteba Mwamba. J.W. (2015). Predicting South African Equity Premium using Domestic and Global Economic Policy Uncertainty Indices: Evidence from a Bayesian Graphical Model. Department of Economics, University of Pretoria, Working Paper No. 201596.

Bekiros, S., Gupta, R., and Kyei, C. (Forthcoming). On Economic Uncertainty, Stock Market Predictability and Nonlinear Spillover Effects. North American Journal of Economics and Finance.

Bekiros, S., Gupta, R., and Majumdar, A. (2015). Incorporating Economic Policy Uncertainty in US Equity Premium Models: A Nonlinear Predictability Analysis. Department of Economics, University of Pretoria, Working Paper No. 201545. 
Bekiros, S., Gupta, R., and Paccagnini, A. (2015). Oil price forecastability and economic uncertainty. Economics Letters, 132, 125-128.

Benigno, G., Benigno, P., and Nisticò, S. (2011). Risk, Monetary Policy, and the Exchange Rate. NBER Macroeconomics Annual, 26(1), 247-309.

Bonaccolto, G., Caporin, M., and Gupta, R. 2015. The dynamic impact of uncertainty in causing and forecasting the distribution of oil returns and risk. Department of Economics, University of Pretoria, Working Paper No. 201564.

Brogaard, J., and Detzel. A. (2015). The asset pricing implications of government economic policy uncertainty. Management Science, 61(1), 3-18.

Brock, W., Dechert, D., Scheinkman, J., LeBaron, B., 1996. A test for independence based on the correlation dimension. Econometric Reviews, 15 197-235.

Ciner, C., Gurdgiev, C., and Lucey, B. M. (2013). Hedges and safe havens: An examination of stocks, bonds, gold, oil and exchange rates. International Review of Financial Analysis, 29, 202-211.

Colombo, V. (2013). Economic Policy Uncertainty in the US: Does it Matter for the Euro Area? Economics Letters 121(1), 39-42.

El Montasser, G., Ajmi, A.N., Chang, T., Simo-Kengne, B.D., André, C., and Gupta, R. (Forthcoming). Cross-Country Evidence on the Causal Relationship between Policy Uncertainty And House Prices. Journal of Housing Research.

Gupta. R., Hammoudeh. S., Modise. M.P., Nguyen. D.K. (2014). Can economic uncertainty, financial stress and consumer sentiments predict US equity premium? Journal of International Financial Markets, Institutions and Money 33, 367-378.

Gupta. R., Pierdzioch. C., and Risse. M. (2015). On International Uncertainty Links: BARTBased Empirical Evidence for Canada. Department of Economics, University of Pretoria, Working Paper No. 201594.

Jeong, K., Härdle, W. K., and Song, S. (2012). A consistent nonparametric test for causality in quantile. Econometric Theory, 28(04), 861-887.

Martin, J.A.J and Urrea, R.P. (2011). The Effects of Macroeconomics and Policy Uncertainty on Exchange Rate Risk Premium. International Business and Economic Research Journal, 6 (3), 29-48.

Karnizova, L., and Li, J.C. (2014). Economic policy uncertainty, financial markets and probability of US recessions. Economics Letters 125, 261-265.

Krol, R. (2014). Economic Policy Uncertainty and Exchange Rate Volatility. International Finance, 17(2), 241-256.

Li. X-L., Balcilar. M., Gupta. R., and Chang. T. (Forthcoming). The Causal Relationship between Economic Policy Uncertainty and Stock Returns in China and India: Evidence from a Bootstrap Rolling-Window Approach. Emerging Markets Finance and Trade. 
Nishiyama, Y., Hitomi, K., Kawasaki, Y., and Jeong, K. (2011). A consistent nonparametric test for nonlinear causality - Specification in time series regression. Journal of Econometrics 165, 112127.

Pilbeam, K. and Langeland, K. N. (2015). Forecasting exchange rate volatility: GARCH models versus implied volatility forecasts. International Economics and Economic Policy, 12,127-142.

Rapach, D. E., and Wohar, M. E. (2006). The out-of-sample forecasting performance of nonlinear models of real exchange rate behavior. International Journal of Forecasting, 22(2), 341-361.

Rossi, B., and Sekhposyan, T. (2015). Macroeconomic Uncertainty Indices Based on Nowcast and Forecast Error Distributions. American Economic Review: Papers \& Proceedings 105(5), 650-655.

Sin, C.Y. (2015). The economic fundamentals and economic policy uncertainty of Mainland China and their impacts on Taiwan and Hong Kong. International Review of Economics and Finance 40, 298-311.

Strobel, J. (2015). On the different approaches of measuring uncertainty shocks. Economics Letters, $134,69-72$. 
Table 1. Summary Statistics

\begin{tabular}{|l|c|c|c|c|c|c|c|c|c|}
\hline & \multicolumn{9}{|c|}{ Statistic } \\
\hline Exchange Rate & Mean & Median & Maximum & Minimum & $\begin{array}{c}\text { Standard } \\
\text { Deviation }\end{array}$ & Skewness & Kurtosis & $\begin{array}{c}\text { Jarque- } \\
\text { Bera }\end{array}$ & $\begin{array}{c}\text { R-value } \\
\text { Australian Dollar }\end{array}$ \\
\hline Brazilian Real & -0.3339 & -0.9591 & 17.3272 & -9.2945 & 3.8962 & 0.8166 & 5.3370 & 53.8529 & 0.0000 \\
\hline Canadian Dollar & -0.2585 & -0.6346 & 47.8615 & -19.1498 & 6.6323 & 2.7087 & 20.0874 & 2128.8020 & 0.0000 \\
\hline Chinese Yuan & -0.1719 & -0.3500 & 12.4491 & -9.1358 & 2.6282 & 0.5413 & 6.3351 & 81.4539 & 0.0000 \\
\hline Euro & -0.0842 & -0.0546 & 0.5226 & -2.0853 & 0.3840 & -2.5089 & 9.9817 & 489.7346 & 0.0000 \\
\hline Hong Kong Dollar & 0.0015 & 0.0038 & 0.4570 & -0.7064 & 0.1334 & -1.0806 & 9.8610 & 342.7988 & 0.0000 \\
\hline Indian Rupee & 0.1141 & -0.0310 & 7.0925 & -6.9390 & 1.9457 & 0.3014 & 6.4181 & 79.8076 & 0.0000 \\
\hline Japanese Yen & -0.2002 & -0.1465 & 8.5528 & -7.7613 & 2.8244 & 0.3062 & 3.3873 & 3.4781 & 0.1757 \\
\hline South Korean Won & -0.0380 & -0.2259 & 12.0744 & -15.3827 & 3.4801 & 0.1916 & 7.0468 & 109.4681 & 0.0000 \\
\hline Malaysian Ringgit & -0.1352 & 0.0000 & 7.1769 & -4.6172 & 1.4115 & 0.7146 & 8.7374 & 231.6136 & 0.0000 \\
\hline Mexican Peso & 0.1617 & -0.0641 & 15.1657 & -6.7183 & 2.7712 & 1.3637 & 8.9055 & 280.3300 & 0.0000 \\
\hline Russian Ruble & 0.2212 & 0.0549 & 19.6397 & -7.1804 & 2.8740 & 2.4796 & 17.2616 & 1510.4050 & 0.0000 \\
\hline South African Rand & 0.1649 & -0.0917 & 15.7639 & -11.5233 & 4.8791 & 0.5445 & 3.5180 & 9.6347 & 0.0081 \\
\hline Swedish Krona & -0.1271 & -0.2286 & 11.0594 & -8.9735 & 3.4543 & 0.0944 & 3.2219 & 0.5624 & 0.7549 \\
\hline Swiss Franc & -0.2641 & 0.0152 & 11.7078 & -12.7467 & 3.2817 & -0.1590 & 4.4081 & 13.8057 & 0.0010 \\
\hline UK Pound & 0.0234 & 0.1191 & 9.7460 & -8.9109 & 2.5381 & 0.2918 & 4.7676 & 22.9548 & 0.0000 \\
\hline
\end{tabular}

Note: $p$-value corresponds to the Jarque-Bera test. 
Table 2. Linear Granger Causality Test

\begin{tabular}{|l|l|l|}
\hline Country & F-statistic & $p$-value \\
\hline Australian Dollar & 0.002 & 0.966 \\
\hline Brazilian Real & 8.201 & $0.005^{* * *}$ \\
\hline Canadian Dollar & 0.480 & 0.490 \\
\hline Chinese Yuan & 3.425 & $0.066^{*}$ \\
\hline Euro & 3.795 & $0.053^{*}$ \\
\hline Hong Kong Dollar & 0.296 & 0.587 \\
\hline Indian Rupee & 1.784 & 0.184 \\
\hline Japanese Yen & 0.962 & 0.328 \\
\hline South Korean Won & 0.030 & 0.862 \\
\hline Malaysian Ringgit & 0.103 & 0.749 \\
\hline Mexican Peso & 0.003 & 0.956 \\
\hline Russian Ruble & 0.000 & 0.989 \\
\hline South African Rand & 0.273 & 0.602 \\
\hline Swedish Krona & 0.381 & 0.538 \\
\hline Swiss Franc & 2.251 & 0.136 \\
\hline UK Pound & 0.120 & 0.730 \\
\hline
\end{tabular}

Note: ${ }^{* * *}$ and ${ }^{*}$ indicates rejection of the null of no Granger causality at 1 and 10 percent level of significance respectively. 
Table 3. BDS Test Statistic

Panel A: AR(1) Model of Exchange Rate Returns

\begin{tabular}{|l|l|l|l|l|l|}
\hline \multirow{2}{*}{ Exchange Rate } & \multicolumn{5}{|c|}{$m$} \\
\cline { 2 - 6 } & 2 & 3 & 4 & 5 & 6 \\
\hline Australian Dollar & $1.79^{*}$ & $3.03^{* * *}$ & $3.04^{* * *}$ & $3.12^{* * *}$ & $3.11^{* * *}$ \\
\hline Brazilian Real & $5.65^{* * *}$ & $5.82^{* * *}$ & $5.17^{* * *}$ & $4.98^{* * *}$ & $4.56^{* * *}$ \\
\hline Canadian Dollar & $2.93^{* * *}$ & $2.91^{* * *}$ & $2.58^{* * *}$ & $2.33^{* * *}$ & $2.18^{* *}$ \\
\hline Chinese Yuan & $5.92^{* * *}$ & $7.66^{* * *}$ & $8.24^{* * *}$ & $8.89^{* * *}$ & $9.53^{* * *}$ \\
\hline Euro & -0.50 & 0.95 & 1.00 & 1.07 & 1.33 \\
\hline Hong Kong Dollar & $2.35^{* *}$ & $2.93^{* * *}$ & $3.82^{* * *}$ & $5.11^{* * *}$ & $5.95^{* * *}$ \\
\hline Indian Rupee & 1.47 & $3.68^{* * *}$ & $3.85^{* * *}$ & $4.77^{* * *}$ & $4.99^{* * *}$ \\
\hline Japanese Yen & -0.04 & -0.61 & -0.02 & 0.26 & 0.28 \\
\hline South Korean Won & $6.27^{* * *}$ & $5.84^{* * *}$ & $5.37^{* * *}$ & $5.19^{* * *}$ & $5.07^{* * *}$ \\
\hline Malaysian Ringgit & $5.71^{* * *}$ & $6.52^{* * *}$ & $6.81^{* * *}$ & $8.31^{* * *}$ & $9.88^{* * *}$ \\
\hline Mexican Peso & $3.81^{* * *}$ & $4.11^{* * *}$ & $3.66^{* * *}$ & $4.37^{* * *}$ & $4.34^{* * *}$ \\
\hline Russian Ruble & $5.25^{* * *}$ & $7.07^{* * *}$ & $7.72^{* * *}$ & $8.78^{* * *}$ & $10.47^{* * *}$ \\
\hline South African Rand & $2.71^{* * *}$ & $2.61^{* * *}$ & $2.62^{* * *}$ & $2.66^{* * *}$ & $2.83^{* * *}$ \\
\hline Swedish Krona & $1.68^{* *}$ & $2.48^{* *}$ & $2.62^{* * *}$ & $2.51^{* *}$ & $2.27^{* *}$ \\
\hline Swiss Franc & 0.78 & 0.63 & 0.43 & 0.35 & 0.22 \\
\hline UK Pound & 0.67 & 1.16 & 1.31 & 1.18 & 0.98 \\
\hline
\end{tabular}

Panel B: Exchange Rate Returns Equation in the VAR(1) Model with EPU Differentials

\begin{tabular}{|l|l|l|l|l|l|}
\hline \multirow{2}{*}{ Exchange Rate } & \multicolumn{5}{|c|}{$m$} \\
\cline { 2 - 6 } & 2 & 3 & 4 & 5 & 6 \\
\hline Australian Dollar & $1.77^{*}$ & $3.04^{* * *}$ & $3.08^{* * *}$ & $3.18^{* * *}$ & $3.17^{* * *}$ \\
\hline Brazilian Real & $6.01^{* * *}$ & $5.97^{* * *}$ & $5.30^{* * *}$ & $4.87^{* * *}$ & $4.28^{* * *}$ \\
\hline Canadian Dollar & $3.15^{* * *}$ & $2.94^{* * *}$ & $2.53^{* * *}$ & $2.32^{* *}$ & $2.23^{* *}$ \\
\hline Chinese Yuan & $6.23^{* * *}$ & $7.45^{* * *}$ & $8.00^{* * *}$ & $8.66^{* * *}$ & $9.30^{* * *}$ \\
\hline Euro & 0.06 & 0.94 & 0.92 & 1.13 & 1.43 \\
\hline Hong Kong Dollar & $2.59^{* * *}$ & $3.27^{* * *}$ & $4.09^{* * *}$ & $5.37^{* * *}$ & $6.27^{* * *}$ \\
\hline Indian Rupee & 1.31 & $3.76^{* * *}$ & $3.90^{* * *}$ & $4.81^{* * *}$ & $5.20^{* * *}$ \\
\hline Japanese Yen & -0.08 & -0.63 & 0.11 & 0.40 & 0.56 \\
\hline South Korean Won & $6.28^{* * *}$ & $5.89^{* * *}$ & $5.40^{* * *}$ & $5.18^{* * *}$ & $5.02^{* * *}$ \\
\hline Malaysian Ringgit & $5.89^{* * *}$ & $6.72^{* * *}$ & $7.08^{* * *}$ & $8.68^{* * *}$ & $10.29^{* * *}$ \\
\hline Mexican Peso & $3.83^{* * *}$ & $4.17^{* * *}$ & $3.73^{* * *}$ & $4.42^{* * *}$ & $4.36^{* * *}$ \\
\hline Russian Ruble & $5.25^{* * *}$ & $7.08^{* * *}$ & $7.73^{* * *}$ & $8.78^{* * *}$ & $10.48^{* * *}$ \\
\hline South African Rand & $2.38^{* *}$ & $2.36^{* *}$ & $2.41^{* *}$ & $2.47^{* *}$ & $2.60^{* * *}$ \\
\hline Swedish Krona & $1.74^{* *}$ & $2.59^{* * *}$ & $2.76^{* * *}$ & $2.65^{* * *}$ & $2.35^{* *}$ \\
\hline Swiss Franc & 0.62 & 0.54 & 0.33 & 0.31 & 0.47 \\
\hline UK Pound & 0.54 & 0.99 & 1.16 & 1.04 & 0.81 \\
\hline Nim
\end{tabular}

Note: $m$ stands for the number of (embedded) dimension which embed the time series into $m$-dimensional vectors, by taking each $\mathrm{m}$ successive points in the series. Value in cell represents BDS $z$-statistic; ${ }^{* * *},{ }^{* *},{ }^{*}$ indicates rejection of i.i.d. residuals at 1,5 and 10 percent levels of significance respectively. 
Table 4. Bai and Perron (2003) Multiple Structural Break Test

\begin{tabular}{|c|c|c|}
\hline & \multicolumn{2}{|c|}{ Break Date(s) } \\
\hline Exchange Rate & $\begin{array}{l}\text { AR(1) Model of Exchange } \\
\text { Rate Returns }\end{array}$ & $\begin{array}{c}\text { Exchange Rate Returns } \\
\text { Equation in the VAR(1) } \\
\text { Model with EPU Differentials }\end{array}$ \\
\hline Australian Dollar & 2008:04, 2008:11 & 2008:04, 2008:11 \\
\hline Brazilian Real & 2002:08, 2007:10, 2009:09 & 2002:08, 2007:11, 2009:10 \\
\hline Canadian Dollar & $2009: 06$ & $2009: 06$ \\
\hline Chinese Yuan & $2010: 05$ & $2010: 05$ \\
\hline Euro & - & 2008:05, 2008:12 \\
\hline Hong Kong Dollar & - & $\begin{array}{c}\text { 2003:04, 2003:11, 2007:11, } \\
\text { 2010:07, 2011:03 }\end{array}$ \\
\hline Indian Rupee & - & $\begin{aligned} 2008: 08, & 2009: 03,2009: 11 \\
& 2011: 08\end{aligned}$ \\
\hline Japanese Yen & - & 2008:11, 2009:06 \\
\hline South Korean Won & $2008: 12$ & $2008: 12$ \\
\hline Malaysian Ringgit & $2008: 12$ & $2008: 12$ \\
\hline Mexican Peso & 2008:08, 2009:03 & 2008:08, 2009:03 \\
\hline Russian Ruble & 2007:03, 2009:02 & $2007: 03,2009: 02$ \\
\hline South African Rand & - & 2001:06, 2002:01, 2005:01 \\
\hline Swedish Krona & $\begin{array}{c}2001: 07,2008: 08,2009: 03, \\
\text { 2009:10 }\end{array}$ & $\begin{array}{c}\text { 2001:07, 2008:08, 2009:03, } \\
\text { 2009:10, 2010:07 }\end{array}$ \\
\hline Swiss Franc & 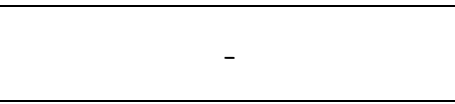 & $\begin{array}{c}\text { 2007:11, 2008:11, 2009:06, } \\
\text { 2010:06, 2011:09 }\end{array}$ \\
\hline UK Pound & 2008:08, 2009:03 & $\begin{array}{c}\text { 2002:02, 2004:03, 2006:04, } \\
\text { 2008:06, 2010:05 }\end{array}$ \\
\hline
\end{tabular}




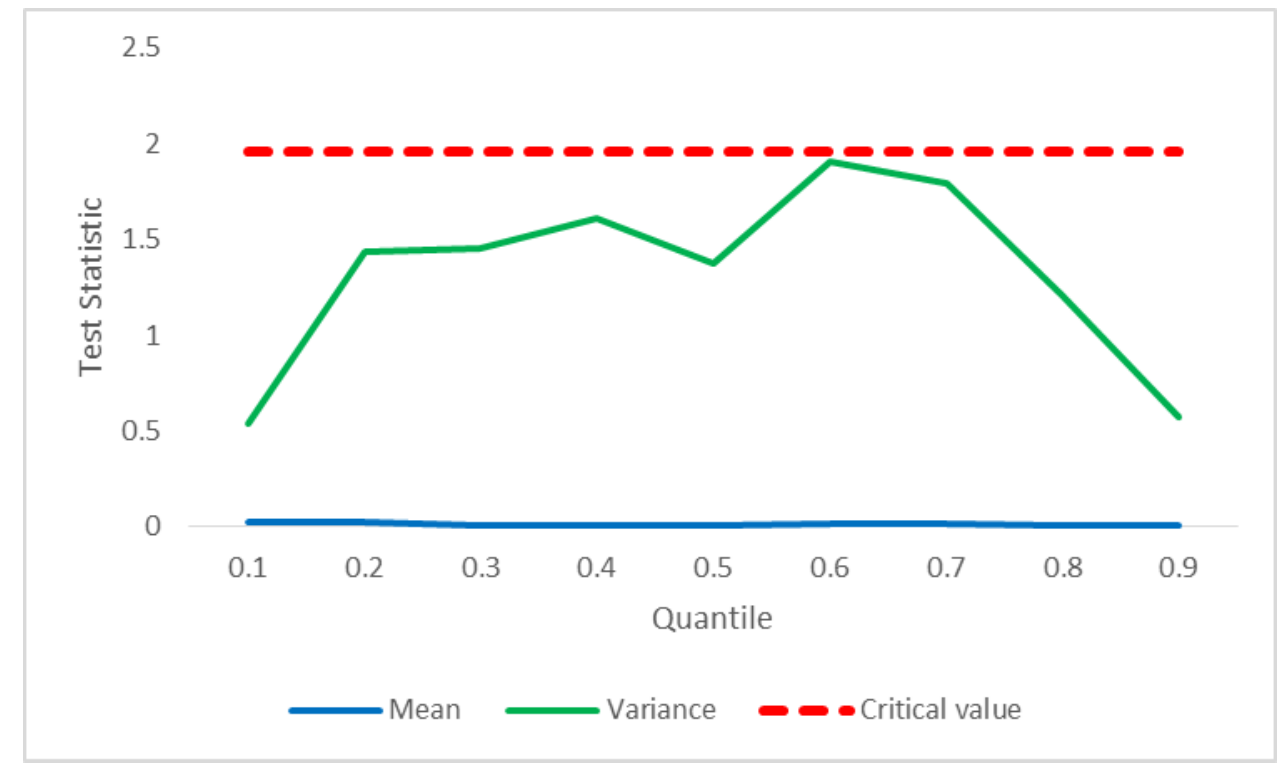

Figure 1: Quantile Causality: Australian Dollar to U.S. Dollar Exchange Rate

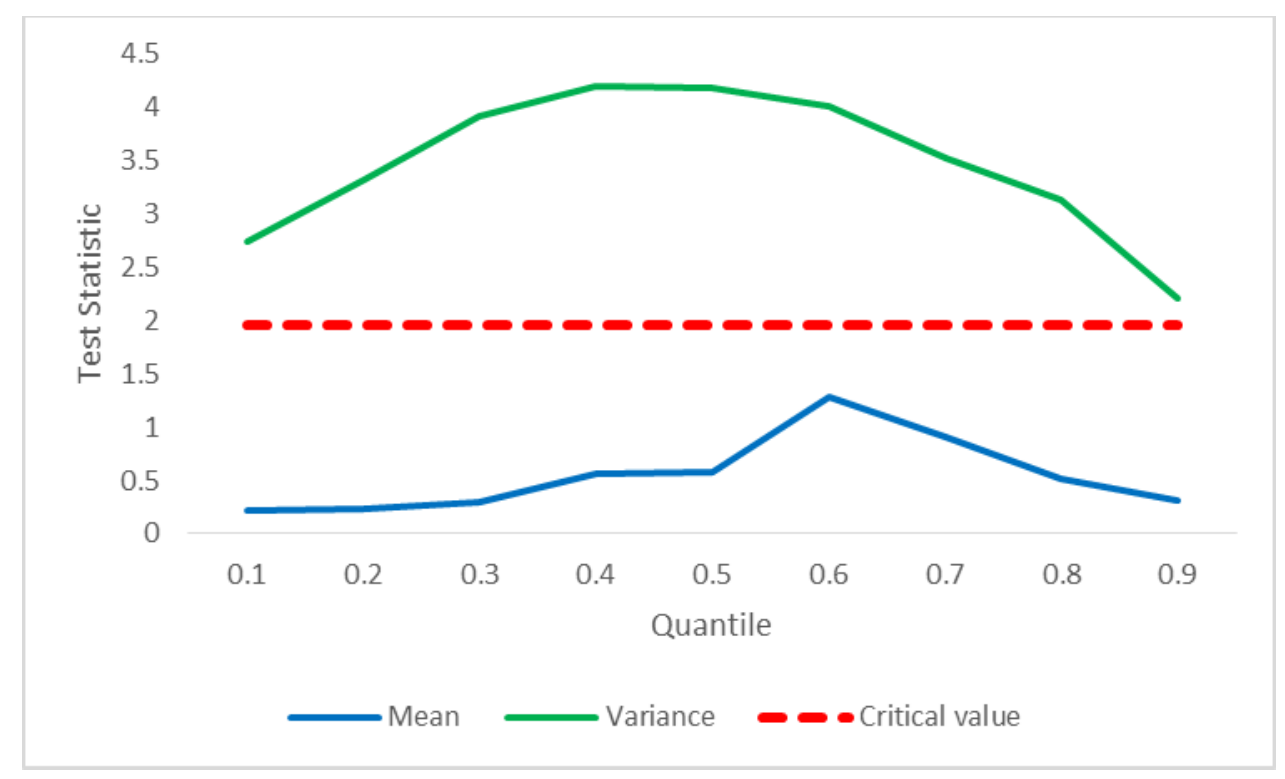

Figure 2: Quantile Causality: Brazilian Real to U.S. Dollar Exchange Rate 


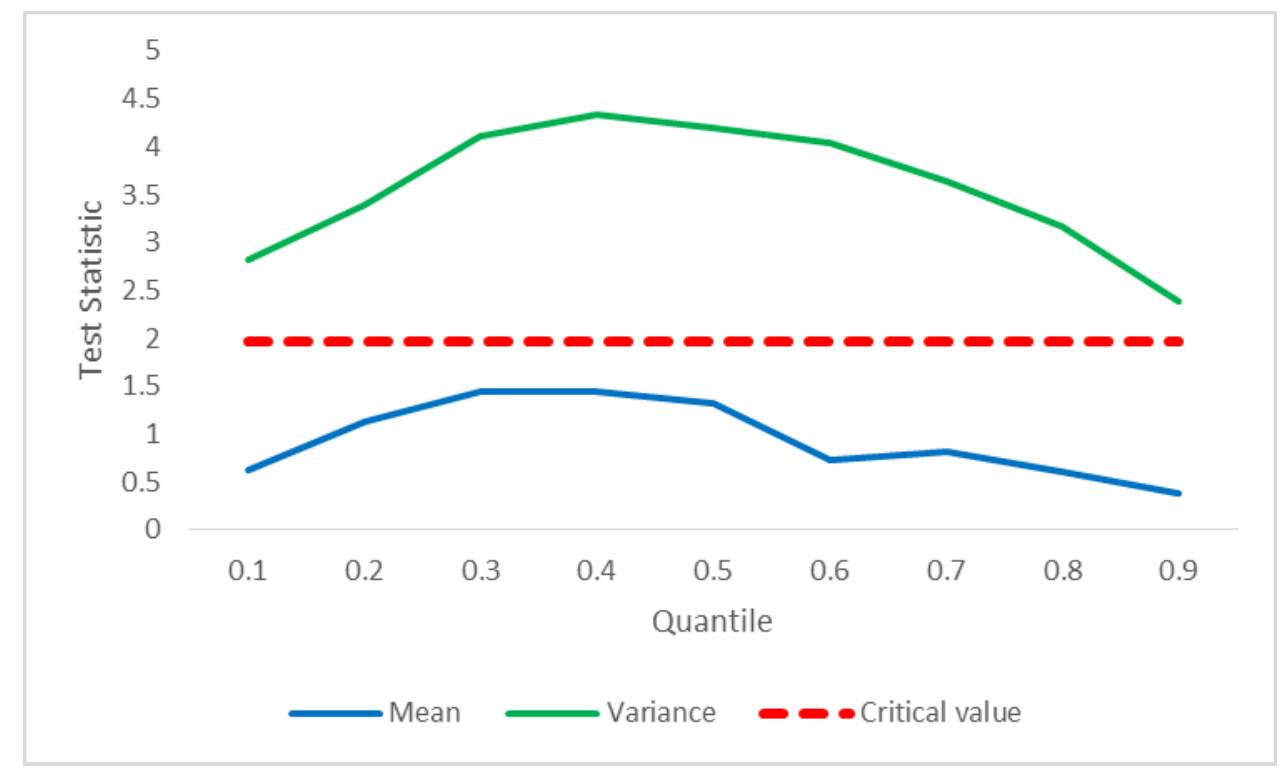

Figure 3: Quantile Causality: Canadian Dollar to U.S. Dollar Exchange Rate

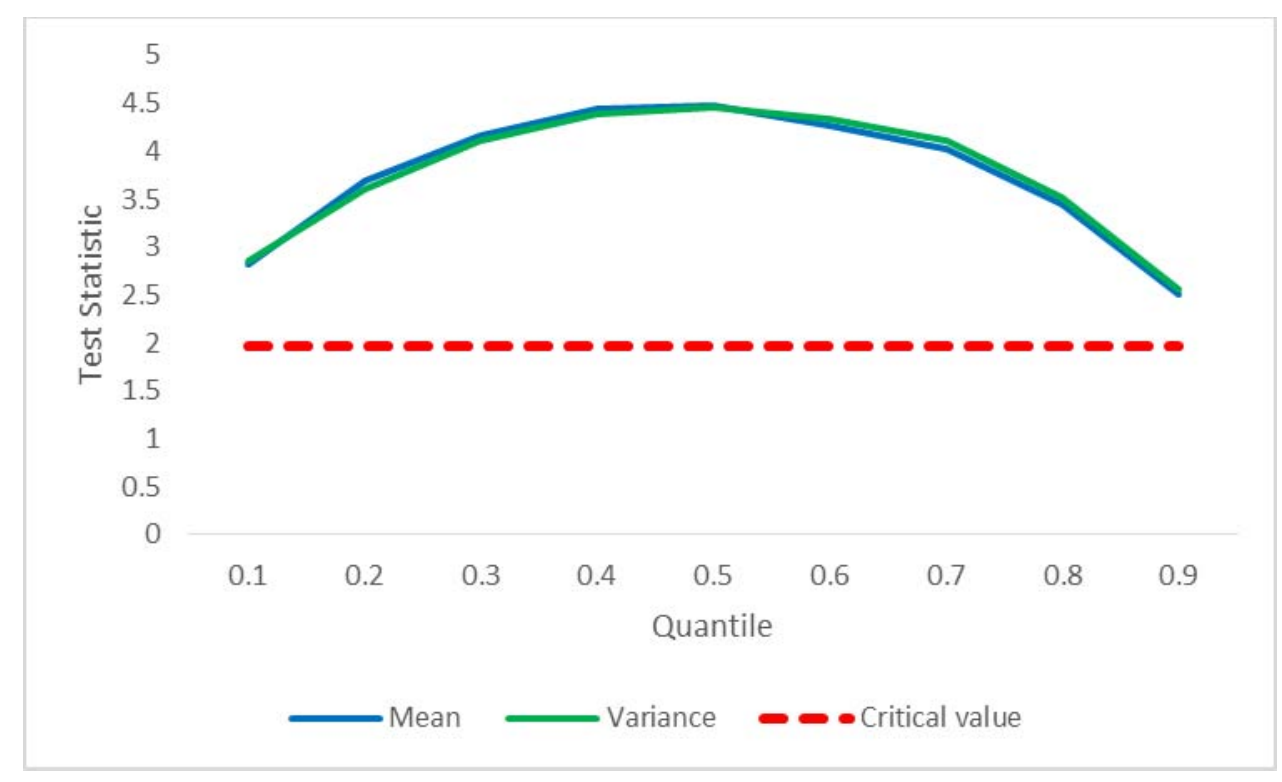

Figure 4: Quantile Causality: Chinese Yuan to U.S. Dollar Exchange Rate 


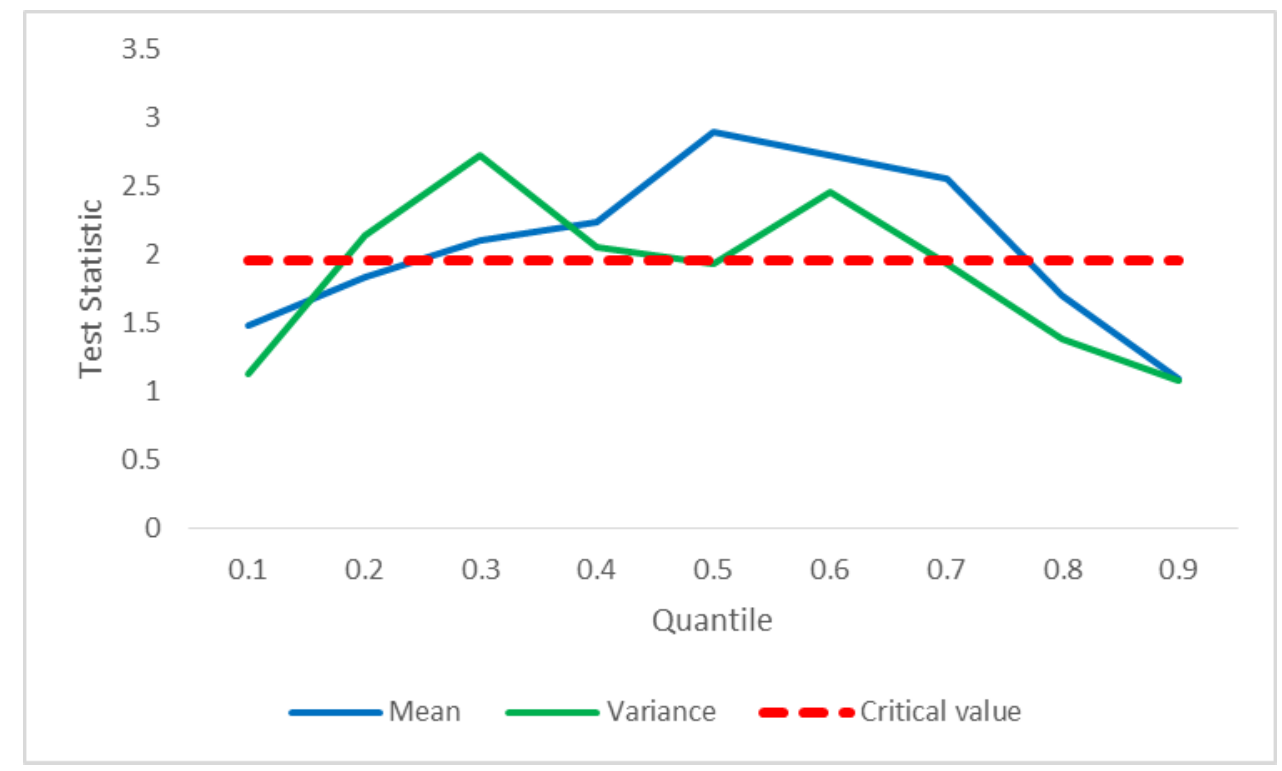

Figure 5: Quantile Causality: Euro to U.S. Dollar Exchange Rate

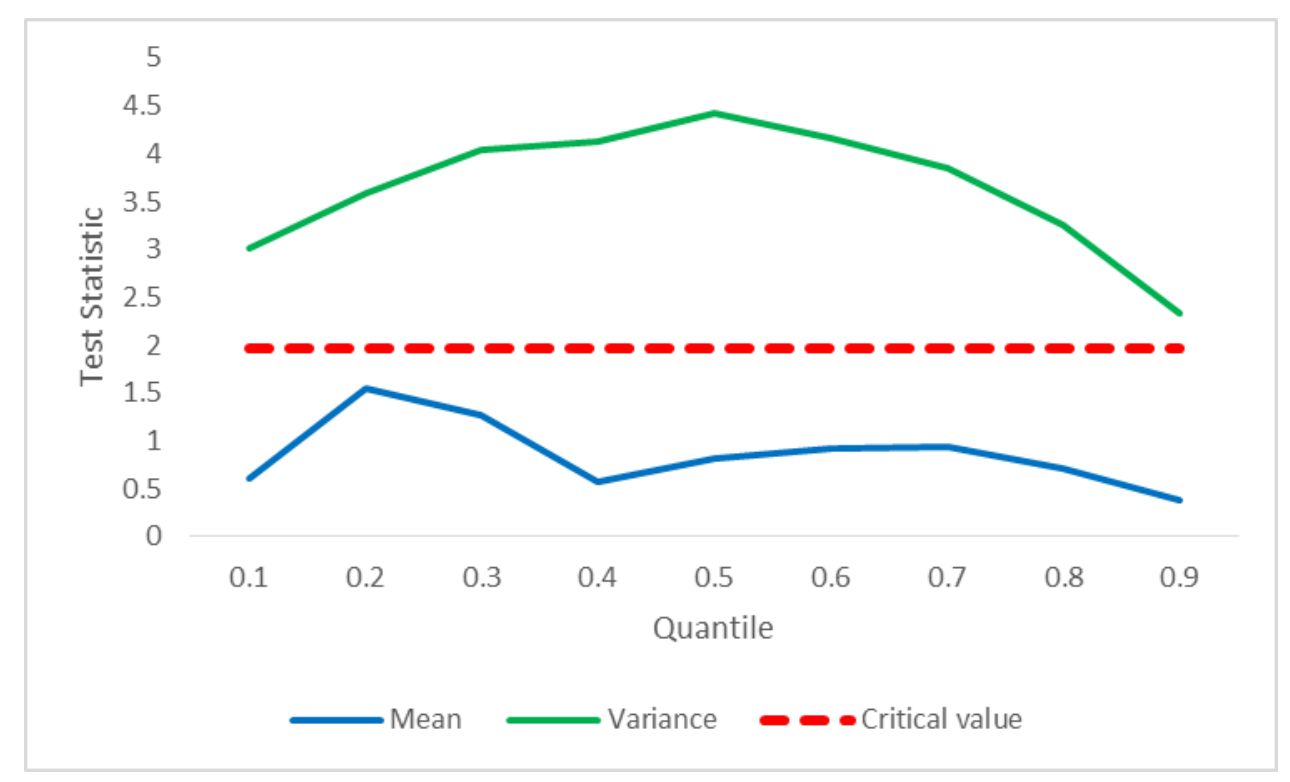

Figure 6: Quantile Causality: Hong Kong Dollar to U.S. Dollar Exchange Rate 


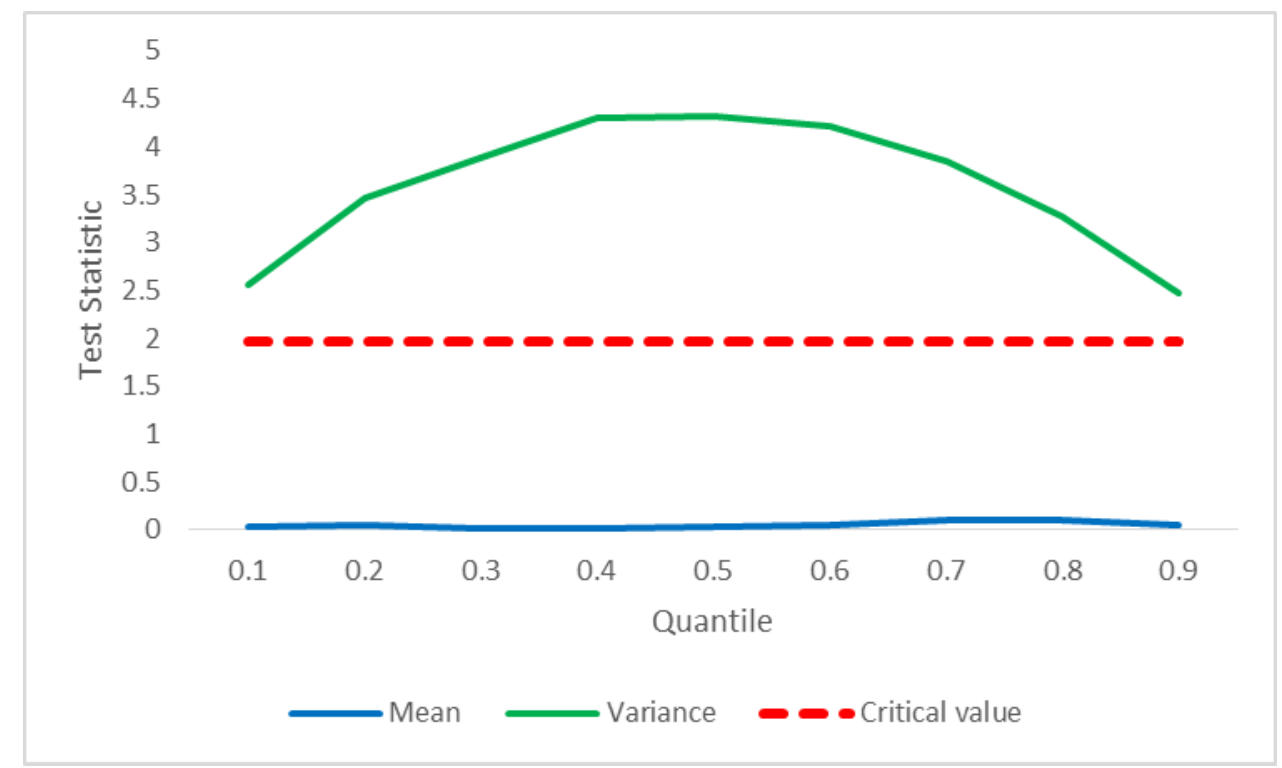

Figure 7: Quantile Causality: Indian Rupee to U.S. Dollar Exchange Rate

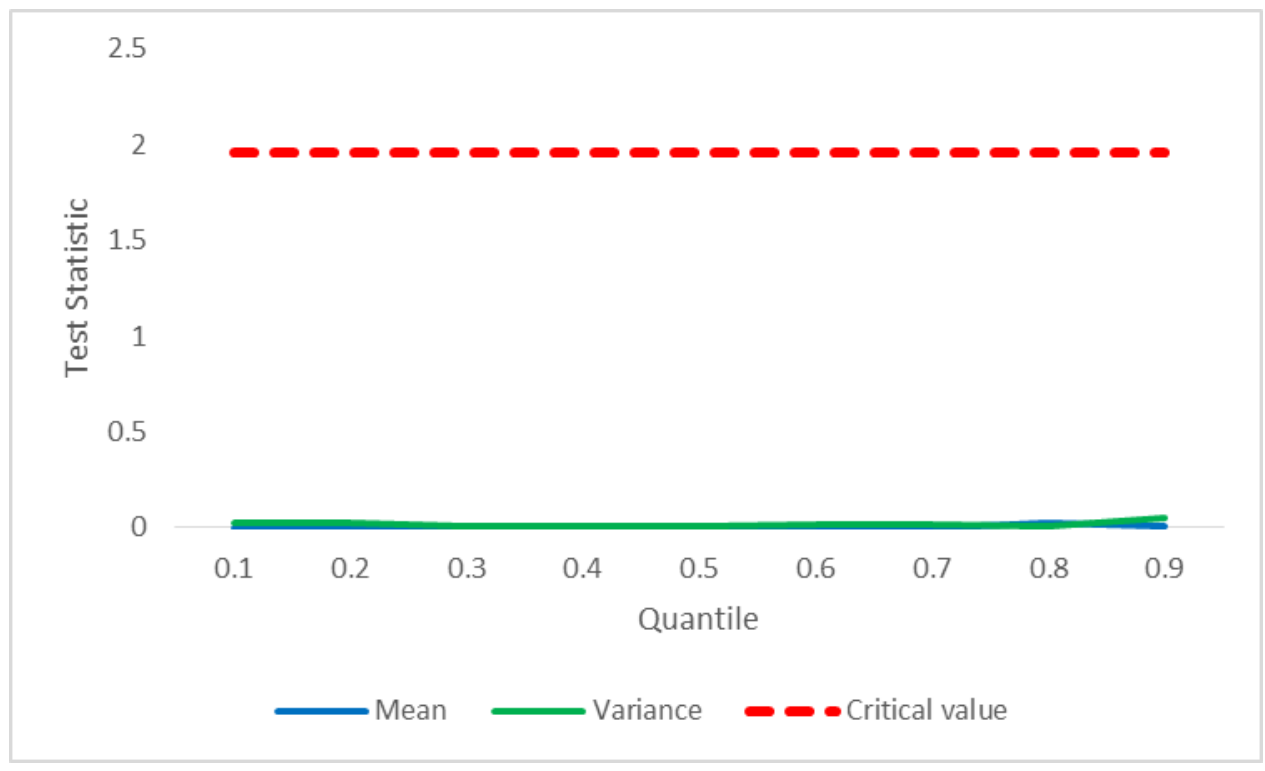

Figure 8: Quantile Causality: Japanese Yen to U.S. Dollar Exchange Rate 


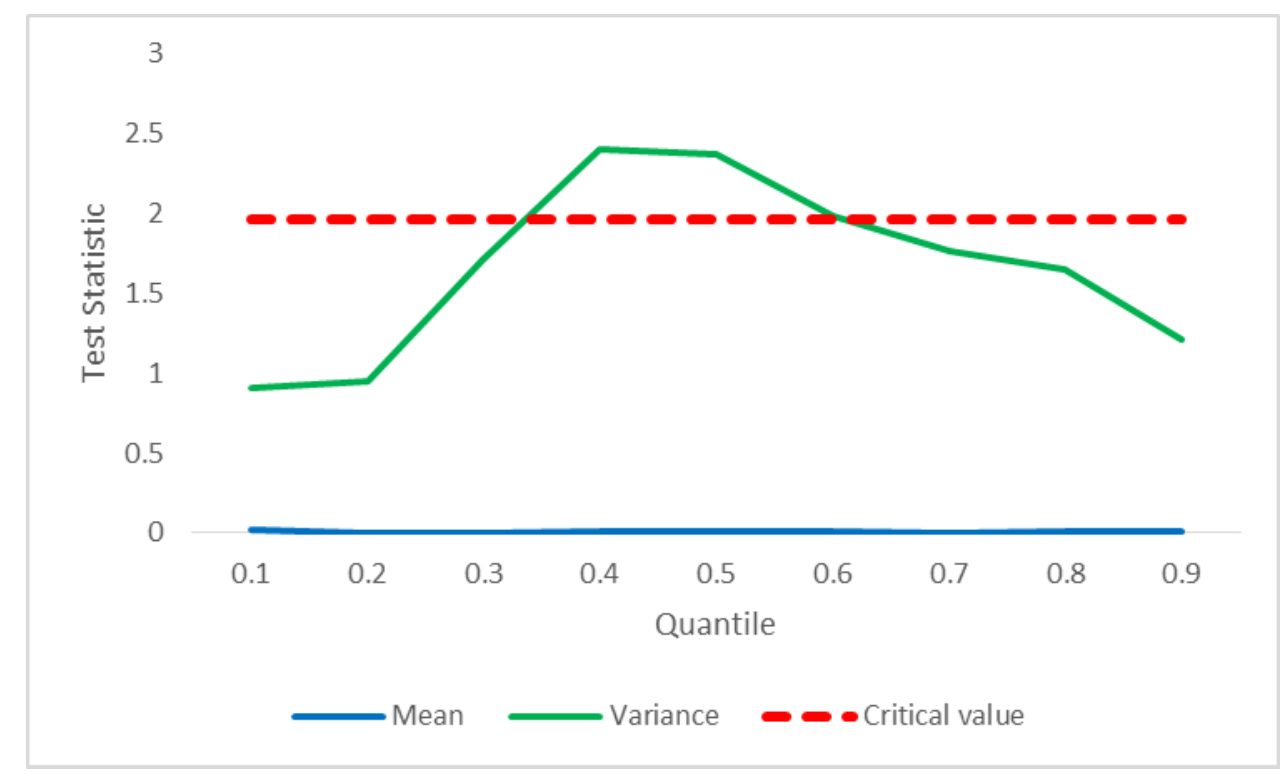

Figure 9: Quantile Causality: South Korean Won to U.S. Dollar Exchange Rate

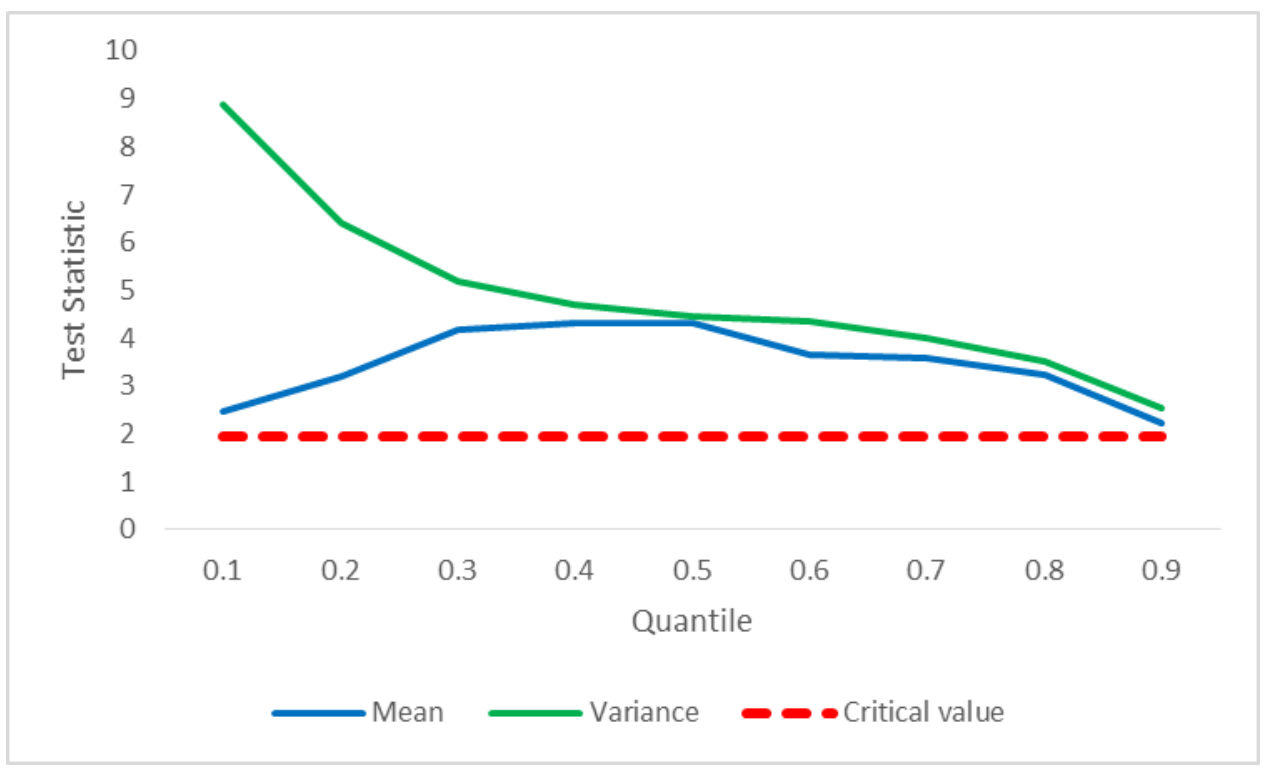

Figure 10: Quantile Causality: Malaysian Ringgit to U.S. Dollar Exchange Rate 


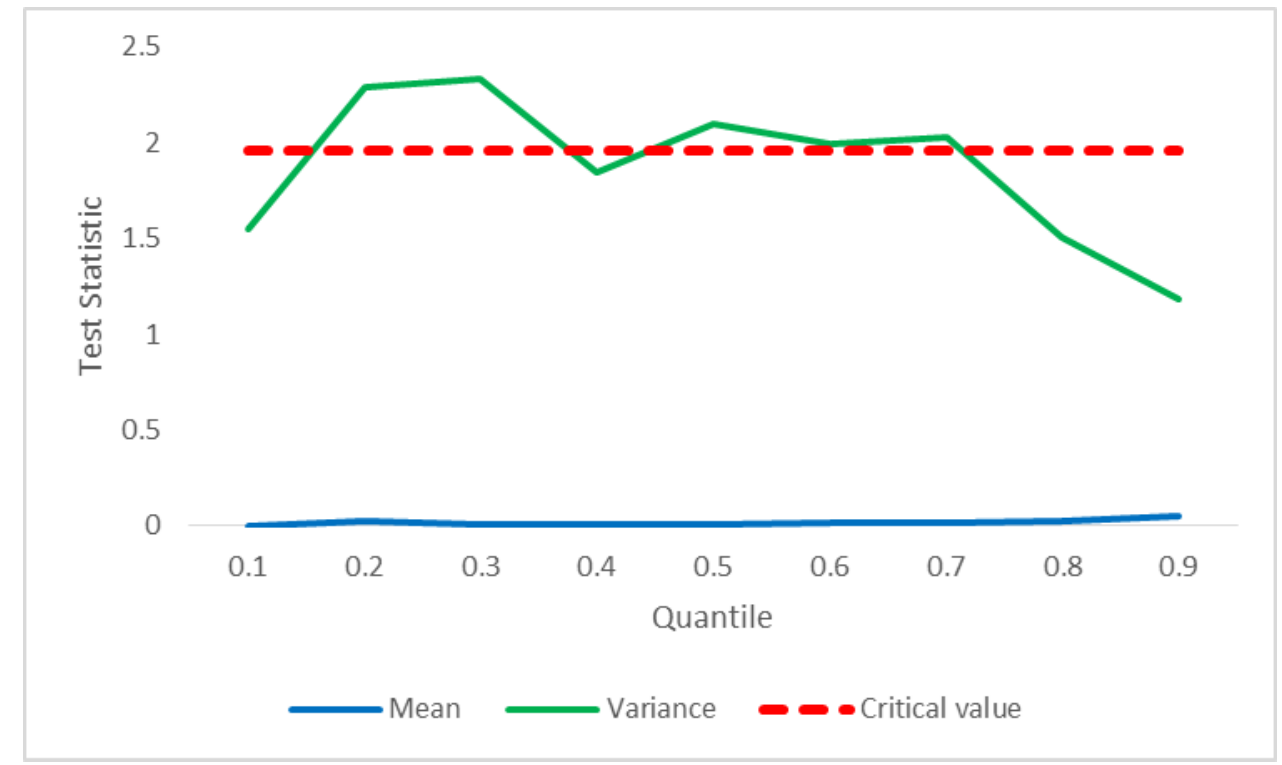

Figure 11: Quantile Causality: Mexican Peso to U.S. Dollar Exchange Rate

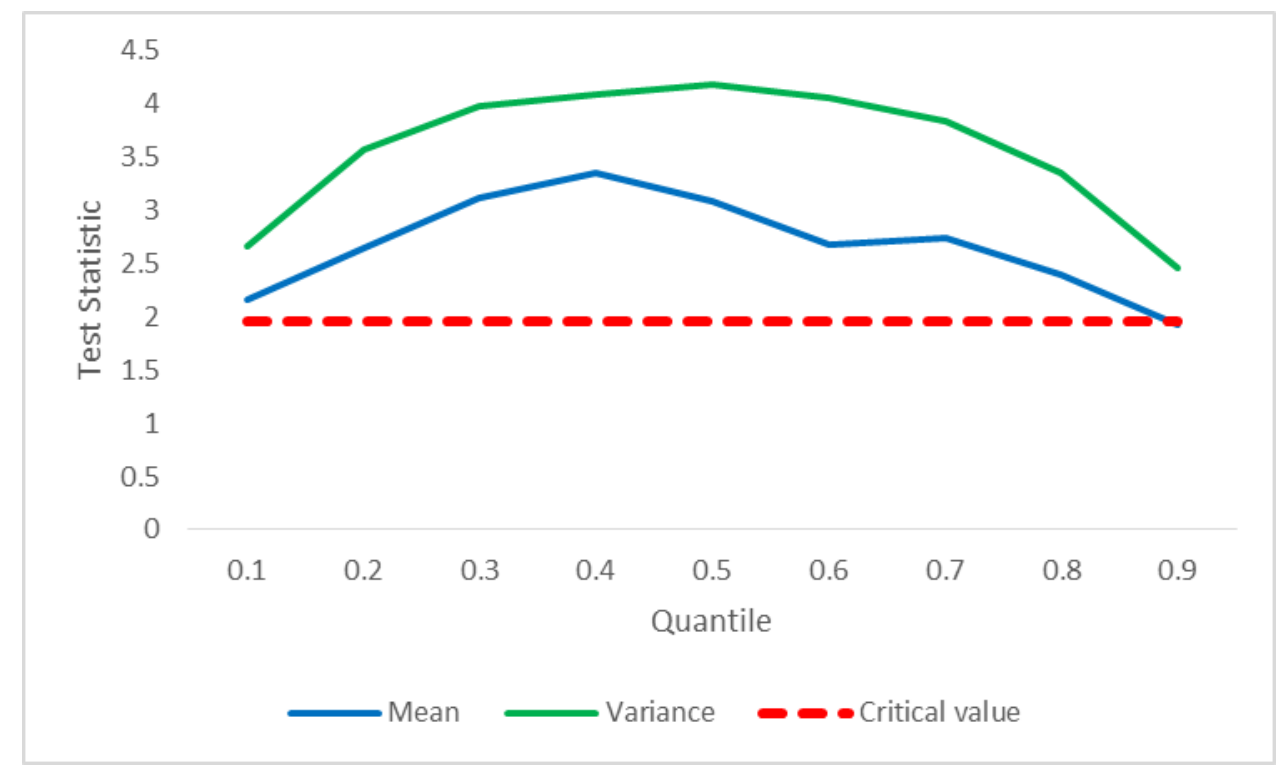

Figure 12: Quantile Causality: Russian Ruble to U.S. Dollar Exchange Rate 


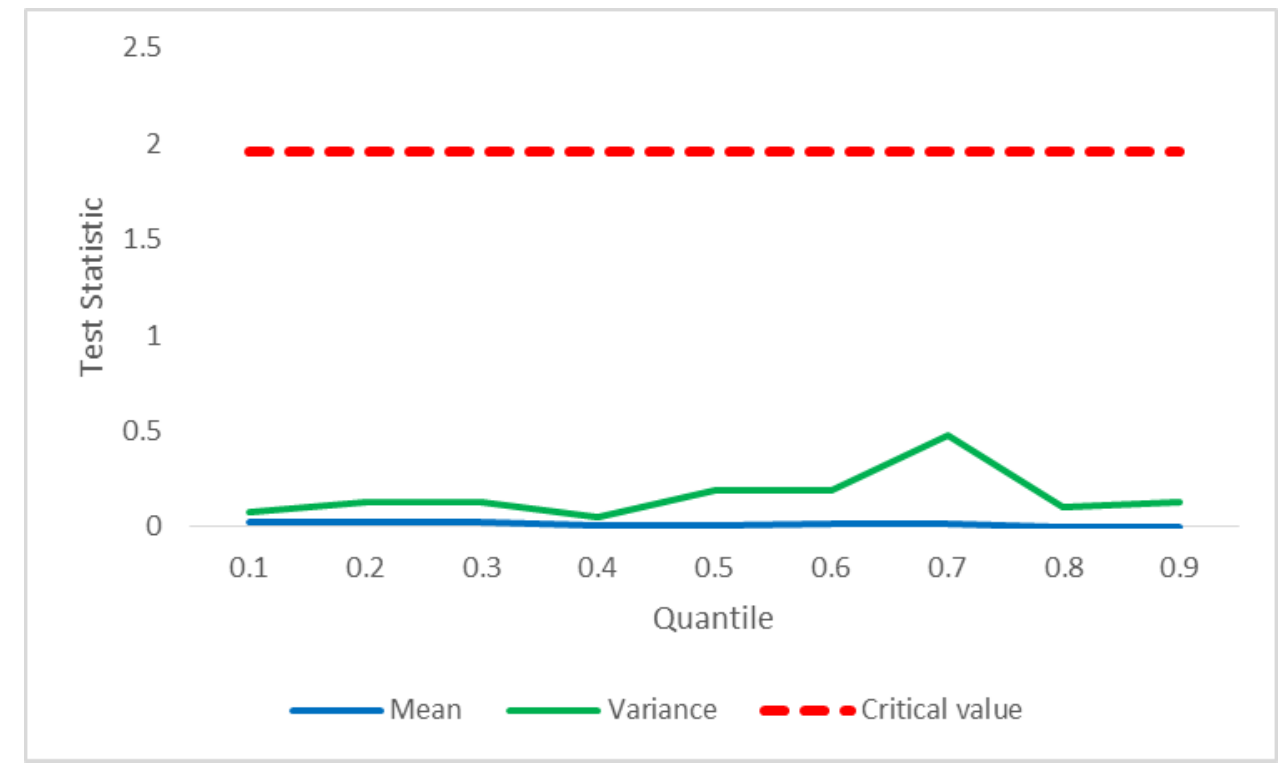

Figure 13: Quantile Causality: South African Rand to U.S. Dollar Exchange Rate

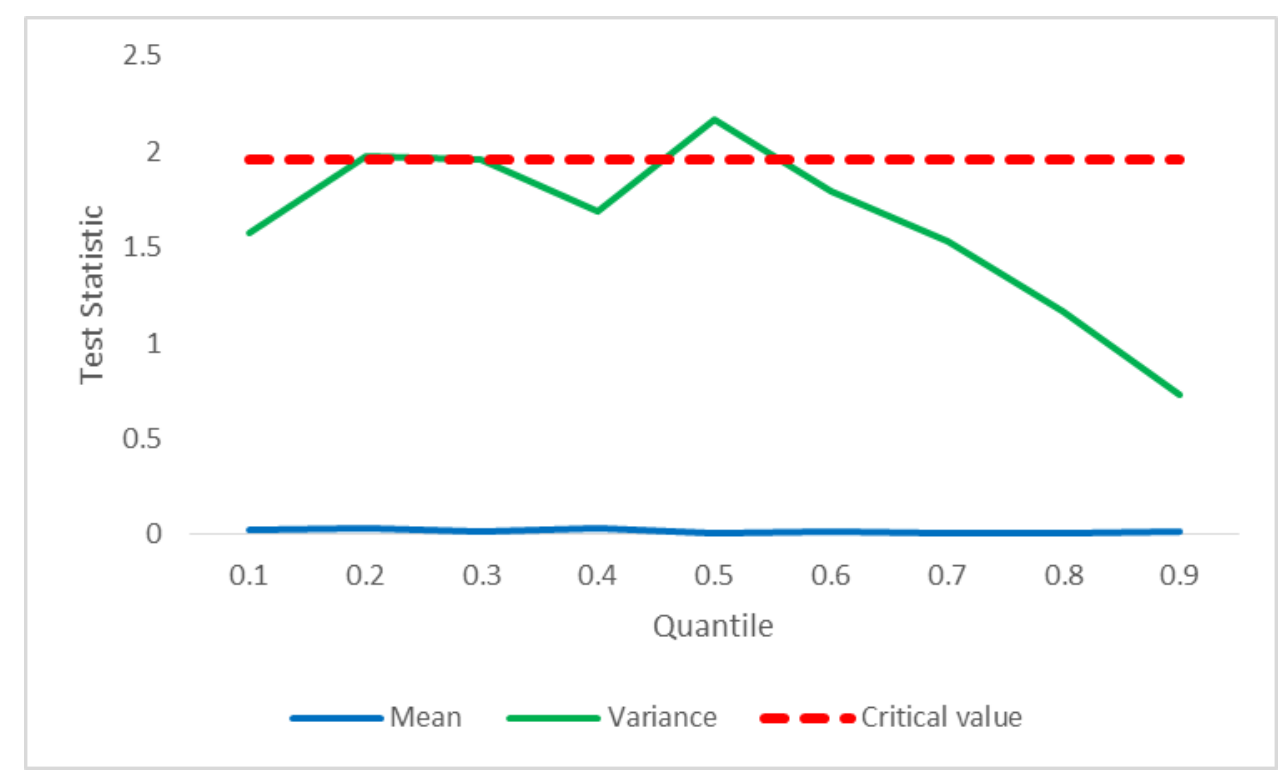

Figure 14: Quantile Causality: Swedish Krona to U.S. Dollar Exchange Rate 


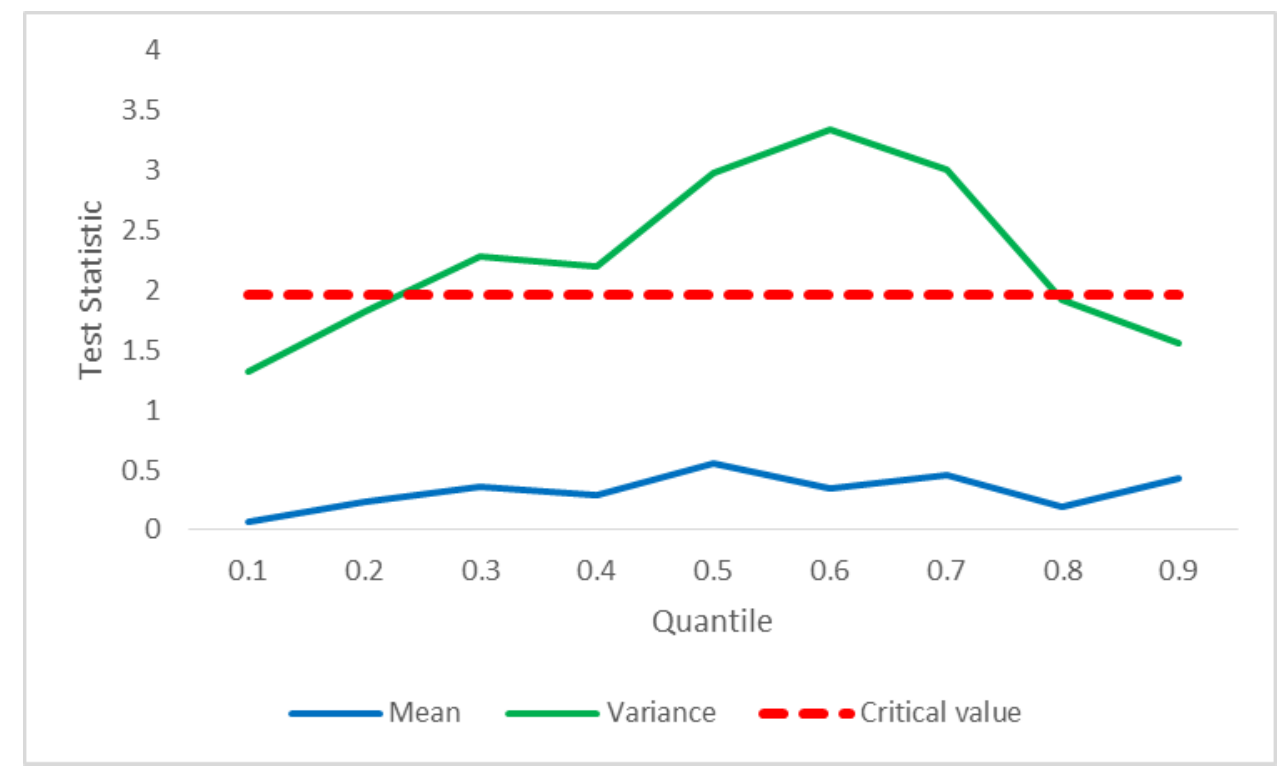

Figure 15: Quantile Causality: Swiss Franc to U.S. Dollar Exchange Rate

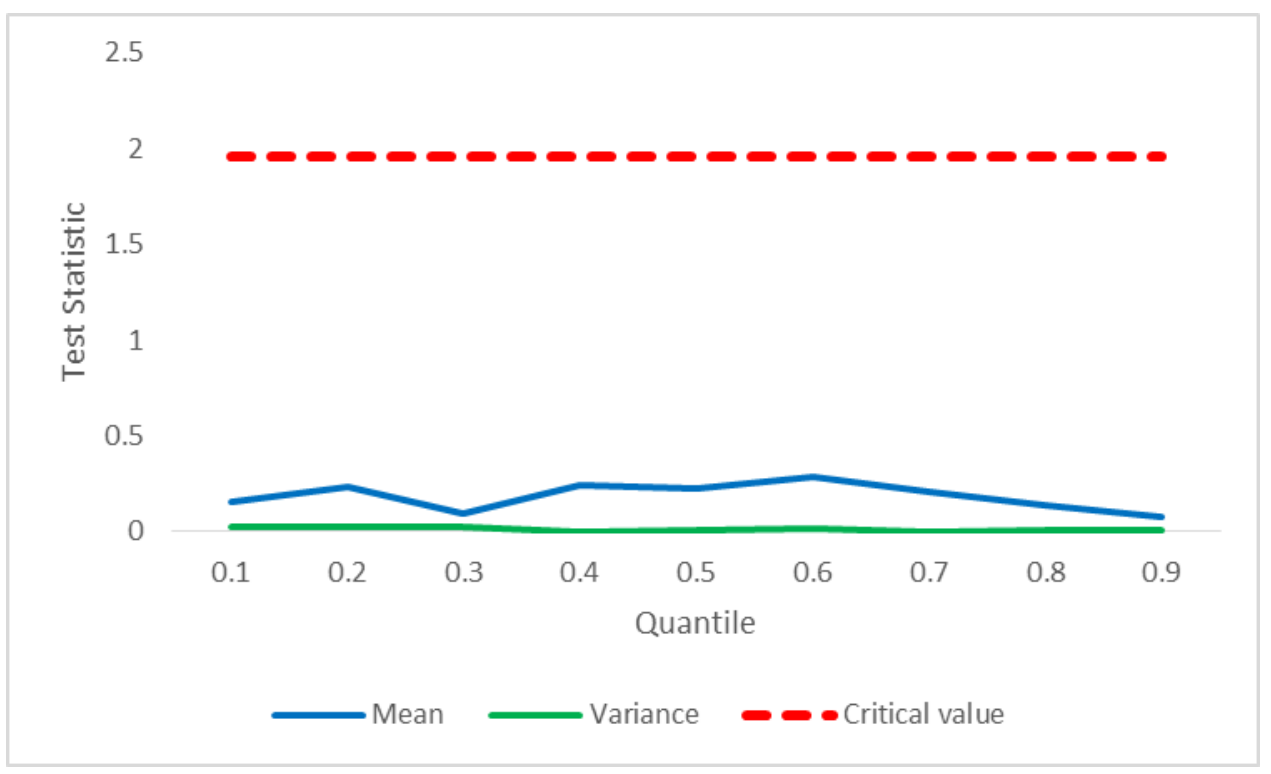

Figure 16: Quantile Causality: British Pound to U.S. Dollar Exchange Rate 